\title{
Recovery of uranium (VI) from concentrated phosphoric acid using bifunctional reagents
}

\author{
Antoine Leydiera, Guilhem Arrachart ${ }^{\mathrm{a}, *}$, Raphaël Turgis ${ }^{\mathrm{a}}$, Gilles Bernier ${ }^{\mathrm{b}}$, Cécile Marie ${ }^{\mathrm{b}}$, Manuel Miguirditchian ${ }^{\mathrm{b}}$, Stéphane \\ Pellet-Rostainga \\ a ICSM-UMR 5257, CEA, CNRS, Univ. Montpellier, ENSCM, Bagnols-sur-Cèze, France \\ b CEA, Nuclear Energy, Research Department on Mining and Fuel Recycling Processes, SMCS, LCPE, Bagnols-sur-Cèze, France \\ *Corresponding author. E-mail: guilhem.arrachart@cea.fr
}

\begin{abstract}
The current standard for the recovery of uranium from phosphoric acid is the so-called URPHOS process, where the solvent is a synergistic mixture of $0.5 \mathrm{M}$ di-2-ethyl-hexyl-phosphoric acid (HDEHP), which is used as a cation exchanger, and $0.125 \mathrm{M}$ tri-n-octyl-phosphine oxide (TOPO), which acts as a neutral donor.

Here, the full synthesis of a novel family of "autosynergistic" molecules that contain a phosphoric acid group, similar to HDEHP, and a phosphine oxide group, similar to TOPO is described. These new bifunctional ligands were tested for the selective recovery of uranium( $\mathrm{VI}$ ) from a $5 \mathrm{M}$ phosphoric acid solution. The association of components of HDEHP and TOPO (a cation exchanger ta neutral donor) in a single molecule improves uranium extraction and its selectivity over iron in comparison to a synergistic mixture of the extractants.
\end{abstract}

\section{Keywords}

Uranium; Phosphoric acid; Solvent extraction; Bifunctional ligands

\section{Introduction}

Wet-process phosphoric acid (WPA) is an important unconventional source of uranium. The quantities of available uranium vary within a deposit and between different mineral fields (from 20 to 200 ppm). Considering the total amount of phosphate rock, uranium recovery from this resource is an alternative to uranium production from uranium ores (Gabriel et al., 2013; Gupta and Singh, 2003; IAEA, 1989; IAEA, 2001). Several methods have been investigated to remove uranium from WPA such as precipitation (Weterings and Janssen, 1985), ion-exchange (Kabay et al., 1998), membrane separation (Mouysset et al., 1983; Singh et al., 2010), solid-liquid (Charlot et al., 2014) and liquid-liquid extraction (Kumar et al., 2011).

The URPHOS system is a successful uranium recovery process that uses a synergistic combination of di(2ethylhexyl)phosphoric acid (HDEHP) as a cationic exchanger and trioctylphosphine oxide (TOPO) as a neutral donor (Hurst et al., 1972). The HDEHP-TOPO solvent is recognized as a better system compared to other processes, such as a mixture of mono and diphenyl phosphoric acid (OPAP) (Hurst and Crouse, 1974) or octyl-pyrophosphoric acid (OPPA) (Khorfan, 1993; Maccready et al., 1981), because it extracts hexavalent uranium $\mathrm{U}(\mathrm{VI})$ and is both more stable and more selective (especially against iron).

A large number of studies have been launched to develop new processes or to improve existing ones (Beltrami et al., 2013a; Beltrami et al., 2013b; Lyaudet et al., 1989; Singh et al., 2001; Singh et al., 2009; Textoris et al., 1987). Many investigators are trying to develop new, more powerful extractants for the selective extraction of uranium from other elements that are present in phosphoric acid, especially iron, the main impurity (Beltrami et al., 2014; Singh et al., 2016). For this purpose, the development of multifunctional molecules has been proposed. Polyphosphorous compounds (di or triphosphonates or triphosphonic acids) (Sturtz, 1984; Sturtz et al., 1984; Tunick et al., 1982) have shown promising extraction properties for $\mathrm{U}(\mathrm{IV})$ (distribution ratio $\mathrm{D}_{U}=25-150$ ), but they are not suitable for the extraction of $\mathrm{U}(\mathrm{VI})$, which results from the reduction of $\mathrm{U}(\mathrm{VI})$ by $\mathrm{Fe}(0)$. Another drawback of these compounds is their poor selectivity with separation factor $\mathrm{SF}_{\mathrm{U} / \mathrm{Fe}}=2.5$.

Another approach is the use of a single molecule or an "autosynergistic" molecule that combines both cationic exchanger and neutral donor functions in a same molecular architecture, although this has been less described in the literature. For example, a combination of phosphoric acid and phosphine oxide functions separated by a polyether chain (Warshawsky and Arad-Yellin, 1988; Warshawsky et al., 1989) provides bifunctional extractants with higher extraction abilities than the URPHOS system. The major drawback of this system is the low selectivity ( $\mathrm{SF}_{\mathrm{u} / \mathrm{Fe}}$ about 68 in the best case). Furthermore, there are some inherent limitations in the use of such phosphate ester functions. For example, they may be hydrolysed under acidic conditions, and a third phase may form during extraction, making it unsuitable as an industrial reagent.

The concept of combining a neutral donor with an acidic extractant to form bifunctional molecules that achieve the selective extraction of uranium from phosphoric acid has been recently explored. Indeed, a new family of bifunctional molecules has been synthesised and studied for the extraction of $\mathrm{U}(\mathrm{VI})$ in phosphoric solutions based on amidophosphonic acid (Turgis et al., 2014b) and amino-phosphonate functional groups (Turgis et al., 2014a). From a structure-activity approach, a specific ligand, butyl-1-[N,N-bis(2-ethylhexyl)carbamoyl]nonyl phosphonic acid (DEHCNPB) has been studied with regard to the 
outstanding results obtained for the selective extraction and the quantitative recovery of uranium compared to the URPHOS reference system.

The design of a flow sheet and the development of a full solvent extraction process using this molecule are under investigation (Miguirditchian et al., 2016). The present work builds upon these recent investigations of combined solvent systems with the development of bifunctional extractants based on a phosphine oxide-phosphonate moiety. Such bifunctional extractants can be assimilated to a mimic of the HDEHP/TOPO synergistic mixture in one entity, where the phosphonate group acts as the cationic exchanger, similar to HDEHP, and the phosphine oxide moiety can be considered as a donor-solvating group, similar to the TOPO in the synergistic system (Fig. 1).<smiles>CP(=O)([O-])O</smiles>

TOPO<smiles>[14CH3]OP(=O)(O)O[Ga]</smiles>
HDEHP

Fig. 1. Structures of ligands and substituents variations studied.

\section{Experimental section}

\subsection{Synthesis of ligands}

The general ligand synthesis procedure and their characterizations are reported in supporting information.

\subsection{Extraction experiments from $\mathrm{H}_{3} \mathrm{PO}_{4}$ solutions}

The first aqueous phase was prepared from a mixture of $250 \mathrm{mg} / \mathrm{L}$ of $\mathrm{U}(\mathrm{VI})$ and $2500 \mathrm{mg} / \mathrm{L} \mathrm{of} \mathrm{Fe}$ (III) (from $\mathrm{UO}_{2}\left(\mathrm{NO}_{3}\right)_{2} \cdot 6 \mathrm{H}_{2} \mathrm{O}$ and $\mathrm{FePO}_{4} \cdot 4 \mathrm{H}_{2} \mathrm{O}$ salts, respectively) in $5 \mathrm{M} \mathrm{H}_{3} \mathrm{PO}_{4}$ solution. The organic phase was prepared by dissolving ligands $(0.1 \mathrm{M})$ in dodecane. The second aqueous phase was prepared from a genuine industrial phosphoric solution $\left(4.5 \mathrm{M} \mathrm{H}_{3} \mathrm{PO}_{4}\right)$ adjusted to around $1 \mathrm{~g} / \mathrm{L}$ of uranium to increase the accuracy of the analytical measurements and be more representative of loaded organic phases in processing conditions. The initial concentrations of metals $(1.2 \mathrm{~g} / \mathrm{L}$ of $\mathrm{U}(\mathrm{VI})$ and $5.1 \mathrm{~g} / \mathrm{L}$ of Fe(III)) were measured by inductively coupled plasma/atomic emission spectroscopy (ICP/AES).

Extractions were performed at $25^{\circ} \mathrm{C}$ by shaking equal volumes of the organic and aqueous phases using a vortex shaker with a thermostated cell for $30 \mathrm{~min}$ (this time is sufficient to reach thermodynamic equilibrium).

After phase separation by centrifugation ( $4000 \mathrm{rpm}$ for $5 \mathrm{~min}$ ), the aqueous phase was analysed by ICP/AES and the organic phase was submitted to two successive stripping steps:

- ammonium oxalate $0.3 \mathrm{M}$ with an aqueous to organic phase $(\mathrm{A} / \mathrm{O})$ volumetric ratio of 1 at $45^{\circ} \mathrm{C}$ for 30 min to back-extract iron;

- sodium carbonate $1 \mathrm{M}$ with $\mathrm{A} / \mathrm{O}=5$ at $45^{\circ} \mathrm{C}$ for the stripping of uranium.

The same experiment was also conducted in a glove box under similar conditions; however, in this case, the initial aqueous phases were spiked with $59 \mathrm{Fe}$ at $50 \mathrm{kBq} / \mathrm{mL}$ to obtain a second, more precise measurement of the iron distribution ratio using gamma-ray spectrometry. The activity of ${ }^{59} \mathrm{Fe}$ was analysed in both phases at equilibrium using a gamma counting spectrometer (CANBERRA, Hyper pure Ge detector).

Distribution ratio $\left(D_{M}=[M]\right.$ org $\left./[M] a q\right)$ and separation factors $\left(S F=D_{M 1} / D_{M 2}\right)$ were determined in the same way to evaluate the efficiency of the molecule to extract uranium with selectivity towards iron.

\section{Results and discussion}

\subsection{Synthesis}

The products were synthesised according to Fig. 2. Di-n-octylphosphine oxide (1a) or di(2-ethylhexyl)phosphine oxide (1b) were prepared from di-n-butylphosphite using the appropriate (alkyl)magnesium bromide (Pogozhev et al., 2013; Williams and Hamilton, 1952). 


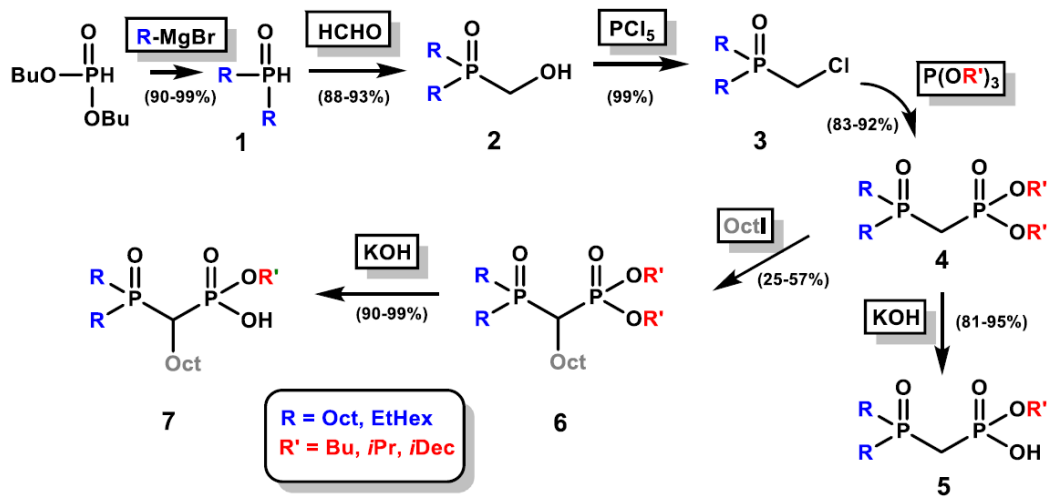

Fig. 2. General synthesis of ligands studied.

The treatment with paraformaldehyde afforded the desired alcohol (2), which was then substituted into a chloride derivative (3) using phosphorus pentachloride ( $\mathrm{PCl}_{5}$ ) (Chauzov et al., 1986). The (chloromethyl) dialkyl-phosphine oxide (3) was then used in an Arbuzov reaction with a suitable trialkyl phosphite (tributyl, triisopropyl, or triisodecyl phosphite). Interestingly, the Arbuzov reaction did not take place between compound 3 bearing an ethylhexyl group and the triisopropyl phosphite under either thermal or microwave conditions.

The corresponding (dialkylphosphoryl)-methyl-(dialkylphosphonate) compounds (4) were then submitted to monosaponification with aqueous potassium hydroxide, resulting in the formation of compounds 5 . The introduction of various alkyl functions on the methylene bridge of compounds 4 by alkylation using a halogenoalkyl compound and sodium hydride can also be performed. At this stage, compound 4 was alkylated by reaction of iodooctane with sodium hydride, affording compounds 6, which can be converted to compounds 7 after monosaponification.

The ligands (Table 1) were isolated from the crude mixture by distillation or by flash chromatography on silica gel and characterized ( ${ }^{1} \mathrm{H}$ and ${ }^{13} \mathrm{C}$ NMR, high-resolution mass spectrometry (HRMS) analysis). The compounds were then used without further purification.

Table 1 (Phosphoryl)-methyl-(phosphonate) derivatives (yields in \%).

\begin{tabular}{|c|c|c|c|}
\hline & Compounds 4 & Compounds & Compounds 7 \\
\hline & 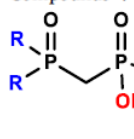 & $\mathrm{R}, \stackrel{\mathrm{O}}{\mathrm{II}}$ & 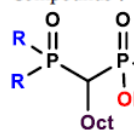 \\
\hline $\mathrm{R}=$ Oct-, $\mathrm{R}^{\prime}=\mathrm{OBu}-$ & $4 a(84 \%)$ & $5 a(79 \%)$ & $7 a(46 \%)$ \\
\hline $\mathrm{R}=$ Oct-, $\mathrm{R}^{\prime}=$ OiPr- & $4 \mathrm{~b}(83 \%)$ & $5 b(75 \%)$ & $7 \mathrm{~b}(21 \%)$ \\
\hline $\mathrm{R}=$ Oct- $\mathrm{R}^{\prime}=$ OiDec & $4 \mathrm{c}(80 \%)$ & $5 c(76 \%)$ & $7 \mathrm{c}(43 \%)$ \\
\hline $\mathrm{R}=\mathrm{EtHex}-, \mathrm{R}^{\prime}=\mathrm{OBu}-$ & 4d $(71 \%)$ & $5 d(64 \%)$ & $7 \mathrm{~d}(32 \%)$ \\
\hline $\mathrm{R}=\mathrm{EtHex}-\mathrm{R}^{\prime}=$ OiDec - & $4 e(65 \%)$ & $5 e(53 \%)$ & $7 \mathrm{e}(31 \%)$ \\
\hline
\end{tabular}

\subsection{Solvent extraction from synthetic $\mathrm{H}_{3} \mathrm{PO}_{4}$ solutions}

Previous studies on amidophosphonate extractants showed that the combination of a C8 chain on the amido part (R) and a C4 chain on the phosphonate function ( $\left.R^{\prime}\right)$ is the best compromise between lipophilicity and viscosity (Turgis et al., 2014b). Therefore, the phosphoryl groups, which are considered as the neutral donor/solvating exchanger part, were systematically chosen as either linear (n-octyl) or branched C8 chains (2-ethylhexyl).

Preliminary screening tests were performed with compound group 5, but no reliable extraction data could be obtained due to the formation of a third phase; in contrast, a third phase was not observed with the corresponding amido-phosphonate ligands (Turgis et al., 2014a).

To avoid the formation of a third phase, $\alpha$-alkylated bifunctional ligands by introducing an alkyl chain on the central methylene bridge have been synthesised. Furthermore, for the amido-phosphonate ligand

DEHCNPB, the monoalkylation of the carbon bridge provides much better selectivity for uranium towards iron (Turgis et al., 2014a). Therefore the influence of an octyl group introduced on the methylene bridge of (dialkylphosphoryl)-methyl(dialkylphosphonate) compounds was studied.

Extraction experiments for ligand group 7 indicate that the introduction of an octyl group on the methylene bridge between the two phosphorus atoms prevents the formation of a third phase, as observed for the corresponding non-alkylated ligands (5); this might be achieved mainly due to the increase in the lipophilicity of the ligand. The extraction of U(VI) and iron from a synthetic phosphoric acid solution ( $5 \mathrm{M}$ ) was investigated for ligand 7 (diluted at $0.1 \mathrm{M}$ in dodecane), and the results are reported in Table 2. Ligands 7 are more efficient than the HDEHP-TOPO reference system for the recovery of uranium(VI) from $5 \mathrm{M}$ phosphoric acid solutions (Table 2). 
Table 2 Distribution ratio and separation factors for the extraction experiments. ${ }^{[a]}$

\begin{tabular}{|c|c|c|c|c|}
\hline & & $D_{U}$ & $\mathrm{D}_{\mathrm{Fe}}$ & $\mathrm{SF}_{\mathrm{U} / \mathrm{Fe}}$ \\
\hline & HDEHP/TOPO & 1.7 & 0.05 & 34 \\
\hline $7 \mathrm{a}$ & Oct, II & 33 & 2.8 & 11.8 \\
\hline 7b & Oct & 50 & 1.6 & 31.2 \\
\hline $7 \mathrm{c}$ & Oct, II & 23 & 1.3 & 17.7 \\
\hline $7 \mathrm{~d}$ & HexEt & 120 & 1.5 & 80 \\
\hline $7 \mathrm{e}$ & HexEt, O & $>120$ & 1.2 & $>100$ \\
\hline
\end{tabular}

${ }^{a}$ Aqueous feed: $250 \mathrm{mg} / \mathrm{L}$ of $\mathrm{U}(\mathrm{VI})+2500 \mathrm{mg} / \mathrm{L}$ of $\mathrm{Fe}(\mathrm{III})$ in $5 \mathrm{M} \mathrm{H}_{3} \mathrm{PO}_{4}$; organic feed: extractant $0.1 \mathrm{M}$ in dodecane; O/A=1.

Furthermore, the distribution ratio for $\mathrm{U}(\mathrm{VI})$ obtained with ligands ( 7$)$ are $>10$ times higher compared to those obtained with the HDEHP/TOPO system. However, the U/Fe selectivity is lower for ligands 7a, 7b, and 7c, which contain an octyl chain on the phosphoryl group. Indeed, the reduction in the U/Fe separation factor corresponds to an increased extraction of Fe(III) to the organic phase compared to the reference system.

Interestingly, a remarkable enhancement in the uranium extraction was obtained for ligands $7 \mathrm{~d}$ and $7 \mathrm{e}$, where the $\mathrm{n}$-octyl chain is substituted by an ethylhexyl chain on the phosphoryl group. This behaviour has been already observed with amidophosphonate based ligands.

\subsection{Solvent extraction from industrial $\mathrm{H}_{3} \mathrm{PO}_{4}$ solutions}

A set of experiments was performed starting from an industrial phosphoric acid solution obtained by the action of sulfuric acid on calcium phosphate rocks (wet-process phosphoric acid [WPA]) (Table 3).

Table 3 Composition of the main elements from the genuine industrial phosphoric acid solution.

\begin{tabular}{llllllll}
\hline Elements & $\mathrm{Al}$ & $\mathrm{Fe}$ & $\mathrm{Mo}$ & $\mathrm{Ti}$ & $\mathrm{U}$ & $\mathrm{V}$ & $\mathrm{Zr}$ \\
\hline Concentration $(\mathrm{mg} / \mathrm{L})$ & 4589 & 5136 & 20 & 43 & 1175 & 460 & 43
\end{tabular}

The extraction experiment was carried out by placing a volume of the genuine phosphoric acid in contact with an equal volume of a 0.1-M solution of ligand 7d (DEHPNPB) diluted in dodecane. The DEHPNPB ligand was chosen for its extraction performance and, also, to compare it with the behaviour of the corresponding amidophosphonate ligand (DEHCNPB). The results are summarized in the Table 4 and the details of the characterizations are given in Tables S1 and S2 (see Supporting information).

Table 4 Distribution ratio and separation factors for the extraction of uranium and iron from genuine industrial phosphoric acid. ${ }^{\text {[a], [b] }}$

\begin{tabular}{|c|c|c|c|c|}
\hline & \multicolumn{2}{|c|}{ DEHPNPB (7d) } & \\
\hline & \multicolumn{2}{|c|}{ EtHex ${ }^{\text {EtHex }}=\underbrace{\text { II }}_{\text {Oct }}$} & \multicolumn{2}{|c|}{ EtHex $_{\text {Ethex }}{ }^{-}$} \\
\hline & $\mathrm{D}_{\mathrm{M}}$ & $\mathrm{SF}_{\mathrm{U} / \mathrm{Fe}}$ & $\mathrm{D}_{\mathrm{M}}$ & $\mathrm{SF}_{\mathrm{U} / \mathrm{Fe}}$ \\
\hline U (ICP) & 99 & - & 107 & - \\
\hline $\mathrm{Fe}(\mathrm{ICP})$ & 0.24 & 411 & $<0.01$ & $>13,000$ \\
\hline $\mathrm{Fe}$ (gamma) & 0.33 & 296 & 0.01 & 11,973 \\
\hline
\end{tabular}

a Aqueous feed: Industrial phosphoric acid solution adjusted to $1 \mathrm{~g} / \mathrm{L}$ of uranium(VI); organic feed: [DEHPNPB] =0.1 M in dodecane; [DEHCNPB] $=0.1 \mathrm{M}$ in TPH; O/A=1, with 30 min shaking at $25^{\circ} \mathrm{C}$.

${ }^{b}$ Distribution ratio in italic were determined using the equation: $D(X)=([X]$ ini $-[X]$ aq. eq. $) /[X]$ aq. eq due to the partial stripping of the element $X$. In other cases, the distribution ratio was determined using the common relationship: $D=[X]$ org. eq. / [X]aq. eq with the results of back-extraction steps.

The affinity for uranium and the trends already observed for the synthetic solutions were confirmed for the extraction experiment performed using a genuine industrial phosphoric acid solution. 
The results clearly show that the ligand exhibits good extraction behaviour with distribution ratio values of $\sim 95$ for $\mathrm{U}(\mathrm{VI})$ and a selectivity against Fe(III)> 300 (Table 4). The results indicate similar extraction behaviour for U(VI) for the phosphine oxidephosphonate ligand (DEHPNPB, $0.1 \mathrm{M}$ in dodecane) and the amidophosphonate ligand (DEHCNPB, $0.1 \mathrm{M}$ in hydrogenated tetrapropylene TPH). However, the substitution of an amido group by its phosphoryl homologue dramatically decreases the selectivity for uranium(VI) towards Fe(III).

This result could be explained by a greater extraction of Fe(III) when a phosphine oxide group is used instead of an amide function (less basic).

Due to this difference, the iron stripping with a $0.3 \mathrm{M}$ solution of ammonium oxalate is less efficient for the phosphorylphosphonate compared to the amidophosphonate ligand. Indeed, some iron remained in the solvent after this first stripping step, and a whitish precipitate was observed during the second stripping step with sodium carbonate. However, the stripping of uranium is more efficient with DEHPNPB. Indeed, with a $1 \mathrm{M}$ solution of sodium carbonate, uranium is totally stripped with an A/O of 1 ; in contrast, an A/O ratio of 5 is necessary for DEHCNPB.

For other impurities (Mo, Zr, V, Al, and Ti), it was not possible to measure distribution ratios with accuracy (due to very low values, interferences, or difficulties in the stripping of those elements from the organic phase). Nevertheless, the extraction of aluminium, vanadium and titanium was very low for both extractants $(D<0.1)$. For other impurities $(\mathrm{Mo}$ and $\mathrm{Zr})$ the extraction could not be correctly quantified here.

\section{Conclusion}

An efficient way to synthesise, in high yield, a new family of bifunctional ligands bearing a cationic exchanger based on a phosphoric group similar to HDEHP and a donor-solvating group based on a phosphine oxide moiety similar to the TOPO in the URPHOS synergistic system has been reported. These "autosynergistic" molecules exhibit higher extraction efficiency for $\mathrm{U}(\mathrm{VI})$ towards Fe(III) from a concentrated phosphoric acid solution compared to the use of two molecules in a synergistic ratio. Moreover, the selective extraction of uranium from phosphoric acid is better than the HDEHP/TOPO system even in the presence of many impurities, as demonstrated in tests with a genuine industrial phosphoric acid solution. Even if the selectivity is lower for the multifunctional ligand with a phosphoryl group in comparison to the amido-derivative, the new phosphine oxide-phosphonate extractants should pave the way towards the efficient extraction of uranium(VI) from concentrated phosphoric acid.

\section{Acknowledgements}

The authors would like to acknowledge the CEA, CNRS, and Univ. Montpellier for their support.

\section{Appendix A. Supplementary data}

Supplementary data to this article can be found online.

\section{References}

Beltrami, D., et al., 2013a. Development of new cationic exchangers for the recovery of uranium (VI) from concentrated phosphoric acid. Sep. Sci. Technol. 48 (3), 480-486.

Beltrami, D., et al., 2013b. Recovery of uranium (VI) from concentrated phosphoric acid by mixtures of new bis(1,3dialkyloxypropan-2-yl) phosphoric acids and tri-n-octylphosphine oxide. Hydrometallurgy 140, 28-33.

Beltrami, D., et al., 2014. Recovery of uranium from wet phosphoric acid by solvent extraction processes. Chem. Rev. 114 (24), 12002-12023.

Charlot, A., et al., 2014. From phosphate rocks to uranium raw materials: hybrid materials designed for selective separation of uranium from phosphoric acid. RSC Adv. 4 (109), 64138-64141.

Chauzov, V.A., Studnev, Y.N., Agafonov, S.V., Fokin, A.V., 1986. Production of chloromethyldiorganophosphine oxides and methoxychloromethyldiorganophosphine oxides. Zh. Obshch. Khim. 56 (12), 2705-2707.

Gabriel, S., Baschwitz, A., Mathonniere, G., Eleouet, T., Fizaine, F., 2013. A critical assessment of global uranium resources, including uranium in phosphate rocks, and the possible impact of uranium shortages on nuclear power fleets. Ann. Nucl. Energy 58, 213-220.

Gupta, C.K., Singh, H., 2003. Uranium Resource Processing: Secondary Resources. Springer, Heidelberg, Germany.

Hurst, F.J., Crouse, D.J., 1974. Recovery of uranium from wet-process phosphoric-acid by extraction with octylphenylphosphoric acid. Ind. Eng. Chem. Process. Des. Dev. 13 (3), 286-291.

Hurst, F.J., Brown, K.B., Crouse, D.J., 1972. Recovery of uranium for wet-process phosphoric- acid. Ind. Eng. Chem. Process. Des. Dev. 11 (1), 122-128.

IAEA, 1989. The Recovery of Uranium from Phosphoric Acid. International Atomic Energy Agency, Vienna, Austria.

IAEA, 2001. Analysis of Uranium Supply to 2050. International Atomic Energy Agency, Vienna, Austria.

Kabay, N., et al., 1998. Recovery of uranium from phosphoric acid solutions using chelating ion-exchange resins. Ind. Eng. Chem. Res. 37 (5), 1983-1990.

Khorfan, S., 1993. Study of the stability of octyl pyrophosphoric acid (OPPA) solvent in the extraction of uranium from phosphoric-acid. Chem. Eng. Process. 32 (5), 273-276. 
Kumar, J.R., Kim, J.S., Lee, J.Y., Yoon, H.S., 2011. A brief review on solvent extraction of uranium from acidic solutions. Sep. Purif. Rev. 40 (2), 77-125.

Lyaudet, G., Du Penhoat, P., Textoris, A., 1989. New developments in extracting uranium contained in phosphoric acid. In: Urphos Bis Process Ind Minerale Mines Carrieres Tech. 71. pp. 168-179.

Maccready, W.L., Wethington, J.A., Hurst, F.J., 1981. Uranium extraction from Florida phosphates. Nucl. Technol. 53 (3), $344-$ 353.

Miguirditchian, M., et al., 2016. Development of a new solvent extraction process based on butyl-1-N,N-bis(2ethylhexyl)carbamoyl nonyl phosphonic acid for the selective recovery of uranium(VI) from phosphoric acid. Solvent Extr. Ion Exch. 34 (3), 274-289.

Mouysset, G., Moliner, J., Lenzi, M., 1983. Utilisation d'une colonne pulsée a disques et couronnes pour l'extraction de I'uranium contenu dans l'acide phosphorique. Hydrometallurgy 11, 165-179.

Pogozhev, D.V., Bezdek, M.J., Schauer, P.A., Berlinguette, C.P., 2013. Ruthenium(II) complexes bearing a naphthalimide fragment: a modular dye platform for the dyesensitized solar cell. Inorg. Chem. 52 (6), 3001-3006.

Singh, H., Vijayalakshmi, R., Mishra, S.L., Gupta, C.K., 2001. Studies on uranium extraction from phosphoric acid using di-nonyl phenyl phosphoric acid-based synergistic mixtures. Hydrometallurgy 59 (1), 69-76.

Singh, S.K., Dhami, P.S., Tripathi, S.C., Dakshinamoorthy, A., 2009. Studies on the recovery of uranium from phosphoric acid medium using synergistic mixture of (2-ethyl hexyl) phosphonic acid, mono (2-ethyl hexyl) ester (PC88A) and tri-n-butyl phosphate (TBP). Hydrometallurgy 95 (1-2), 170-174.

Singh, S.K., Misra, S.K., Tripathi, S.C., Singh, D.K., 2010. Studies on permeation of uranium (VI) from phosphoric acid medium through supported liquid membrane comprising a binary mixture of PC88A and Cyanex 923 in n-dodecane as carrier. Desalination 250 (1), 19-25.

Singh, D.K., Mondal, S., Chakravartty, J.K., 2016. Recovery of uranium from phosphoric acid: a review. Solvent Extr. Ion Exch. 34 (3), 201-225.

Sturtz, G., 1984. Extraction of uranium with diphosphonic compounds. US Patent 4460548.

Sturtz, G., Pensec, T. and Gautier, J.-C., 1984. Extraction of uranium with triphosphonic esters. US Patent 4464346.

Textoris, A., Lyaudet, G., Bathelier, A., 1987. Extraction Process for Separating Iron From Organic Solutions Containing Uranium. EP 0239501.

Tunick, A.A., Largman, T. and Sifniades, S., 1982. Extraction of uranium values from phosphoric acid. US Patent 4316877.

Turgis, R., et al., 2014a. Carbamoylalkylphosphonates for dramatic enhancement of uranium extraction from phosphates ores. Solvent Extr. Ion Exch. 32 (7), 685-702.

Turgis, R., et al., 2014b. Uranium extraction from phosphoric acid using bifunctional amido-phosphonic acid ligands. Solvent Extr. Ion Exch. 32 (5), 478-491.

Warshawsky, A., Arad-Yellin, R., 1988. Difunctional Organophosphorus Extracting Agents and Polymers for Uranium Recovery. FR 2604919.

Warshawsky, A., Kahana, N., Aradyellin, R., 1989. O methyl-dihexyl-phosphine-oxide O' hexyl-2-ethyl phosphoric-acid - a bifunctional extractant combining the properties of phosphine oxide and ester of phosphoric-acid. Hydrometallurgy 23 (1), 91-104.

Weterings, K., Janssen, J., 1985. Recovery of uranium, vanadium, yttrium and rare-earths from phosphoric-acid by a precipitation method. Hydrometallurgy 15 (2), 173-190.

Williams, R.H., Hamilton, L.A., 1952. Di-normal-alkylphosphine oxides. 1. Synthesis. J. Am. Chem. Soc. 74 (21), 5418-5420. 